\title{
Optimization Model Schedule Nervousness in Flight Catering Industry
}

\author{
Aditya Putra Rahardjo \\ Department of Technology Management, Institut Teknologi Sepuluh Nopember, Surabaya, Indonesia \\ e-mail: adityaputrarahardjo@gmail.com
}

\begin{abstract}
Instability often occurs in production planning, which is also known as schedule nervousness. This phenomenon triggers companies to make various efforts in minimizing the level of instability. In this study, the author tries to look at the schedule nervousness problems of the aviation catering industry in determining the amount of production planning to increase profits. In the context of schedule nervousness, there is a very high difference between the value of the temporary demand which is known 10 hours before with the fix order when the airline has closed the check-in process. This phenomenon makes the aviation catering company must bear the loss in value of the difference in demand that occurs. In one month the company must bear the loss of at least 500 packs of food. Based on those problems, the author tries to make an optimization model with linear programming by determining the number of orders for each airline and class of passengers at a certain service level to produce minimal inventory with large profits. The completion of the model using Lingo software is running well and has produced an optimal solution. The potential cost reduction carried out in the first week of January 2020, has provided the best scenario with the potential for cost savings of the production process around the production cost of around $R p 53$ million or about $23 \%$.
\end{abstract}

Keywords-Schedule Nervousness, Production Planning, Optimization, Inventory.

\section{INTRODUCTION}

$\mathrm{T}$ HE problem of an activity instability in production scheduling (commonly known as schedule instability or schedule nervousness) has been an interesting topic of discussion for researchers over the past four decades [1]. This is because schedule nervousness is considered as a trigger indicator in the dimension of measuring the performance of the supply chain specifically in manufacturing companies that have production floors in it.

Instability in production scheduling is a condition of scheduling incompatibility with actual conditions on the production floor. On the other hand, many researchers interpret this condition as nervousness. Grubbstrom and Tang [2] assessed a nervousness condition due to rescheduling done at the top - item level so that there is a change in the level of items below it or lower level of items.

There are many causes that could lead to a change ininitial planned schedule and finally result in schedule instability. Categorized the causes of schedule instability into two groups, which are uncertainty in demand and uncertainty in supply; uncertainty in demand e.g. an adjustment in the production quantity, where as uncertainty in supply could be the temporarily unavailability of machines, production over run or delays the supplier etc.

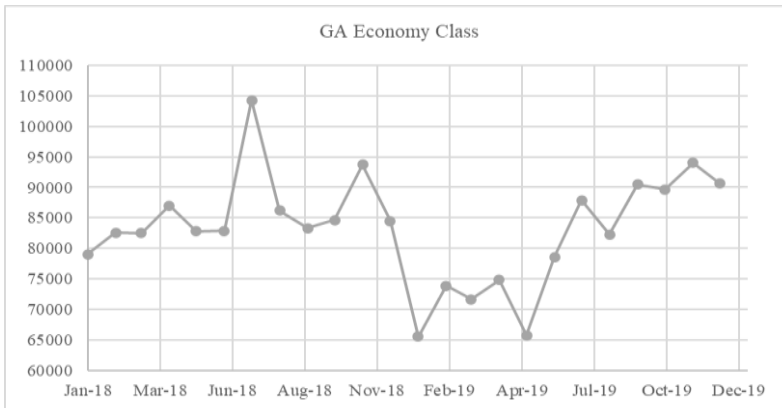

Figure 1. Instability of demand on one of the airlines.

Based on the contract of employment between the company and the airline related to the payment of the amount of food orders, that the airline only pays a number of passengers who have passed the check-in process or called pax on board (POB). Of course this becomes a disadvantage for catering providers who have to bear the price difference between pax on board (POB) and meals on board (MOB). The following table shows the summary order in the first week of December for GA airlines, where Over supply on the third day can no longer be used for the fourth day because the food menu has changed. Here is a graph of requests from one of the airlines, showing volatile demand as seen in Figure 1 below.

In this study the authors tried to look at the problem of schedule nervousness in this context is the existence of a very high level between pax on board (POB) and meals on board (MOB). Production planning is very important in the industrial environment as an effort to efficiency, scheduling and coordination in achieving optimum goals [3].

By looking at this problem the author tries to create an optimization model so that it can formulate problems related to the difference between pax on board (POB) and meals on board (MOB), so that later the company can reduce the value of over supply to a minimum and minimize the cost losses caused.

\section{METHOD}

This research used the case study of an airline catering company in Thailand, which will be referred to here as Company $\mathrm{X}$. This company is involved with servicing customers for both domestic and international airlines at Juanda International airport, Surabaya, Indonesia, with food and non-food items (e.g. towels, newspapers, amenity kits, etc.). Their operations start from the flight landing until departure from the airport; firstly producing in-flightmeals, then assembling both food and non-food products, and finally loading and unloading from the aircraft. Figure 2 below is the 


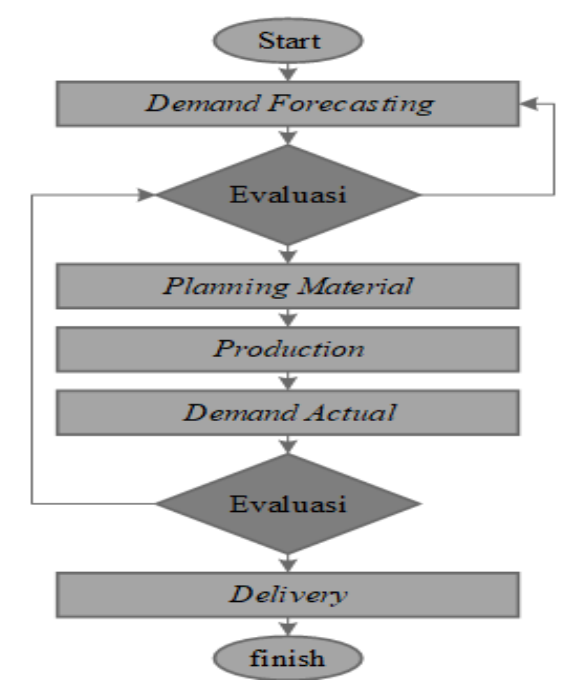

Figure 2. Planning productions process flow

flow of process diagrams in the planning production department.

As mentioned earlier, the exact amount of food will only be known a few hours before the departure time. So, the forecasting department issued a master production scheduling (MPS) based on the amount of meal ordered in the past. MPS will be issued one weeks before the flight. The length of each horizon planning is seven days. Once the MPS is published, one copy will be distributed to the material planning department, which typically buys inputs estimated about seven days in advance. Other copies will be distributed to the production department to plan for optimal labor use, machinery, and work schedules.

The data used in this study was collected over two years from January 2018 to December 2019 by comparing between the planned initial schedule and actual production. Any accessible production revisions, which are amended from the chedule plan, will be measured into a schedule instability. A total of 5000 orders were produced in one day, but only 4550 orders were executed as scheduled.

Pujawan [1] proposed the idea that each type of change should becalculated with the different weight, since the differenttypes of changes caused a different impact to the production operations and hence, the instability in thisresearch was quantified by the approach of, which can be calculated by using the following notations:

- $\quad$ Decision Variables

$\mathrm{X}_{\mathrm{ijt}}=$ Number of airline products $\mathrm{i}$ for class $\mathrm{j}$ in $\mathrm{t}$ period

$\mathrm{I}_{\mathrm{ijt}}=$ Number of airline product inventory $\mathrm{i}$ for class $\mathrm{j}$ in $\mathrm{t}$ period

$\mathrm{Y}_{\mathrm{ijt}}=1,1$, order airline products $\mathrm{i}$ in class $\mathrm{j}$ for period $\mathrm{t}$ $=0$, otherwise

$\mathrm{F}_{\mathrm{ijt}}=1$, excess order on the airline $\mathrm{i}$ in class $\mathrm{j}$ for the period $\mathrm{t}$

$$
\begin{aligned}
& =0, \text { otherwise } \\
& \text { Index }
\end{aligned}
$$

$\mathrm{i}=$ airline type

$\mathrm{j}=$ class type on airline (economy $\&$ business)

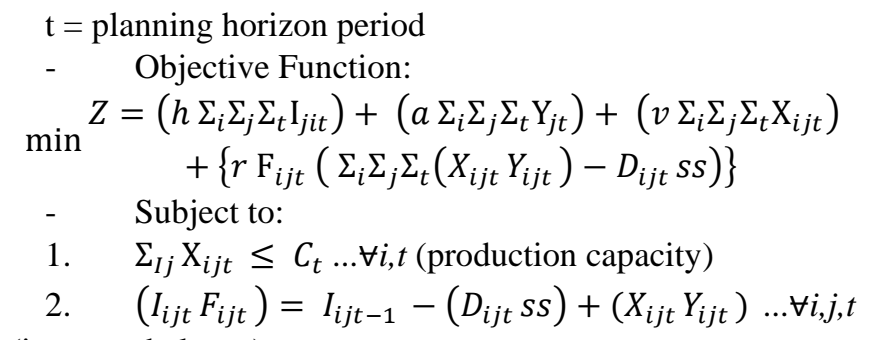
(iventory balance)

3. $\left(X_{i j t} Y_{i j t}\right)-D_{i j t} s s \leq M F_{i j t} \quad \ldots \forall i, j, t \quad$ (to much demand)

- Parameters:

$\mathrm{D}_{\mathrm{ijt}}=$ product demand on the airline $\mathrm{i}$ for class $\mathrm{j}$ at the time

$\mathrm{t}$

$\mathrm{C}_{\mathrm{t}}=$ production capacity at the time $\mathrm{t}$

$\mathrm{a}=$ fixed ordering cost

$\mathrm{v}=$ variable production unit cost

$\mathrm{h}=$ variable holding cost

$\mathrm{r}=$ variable cost charged due to over-production

ss $=$ service level

The completion of the optimization model is done by using the help of LINGO programming. The modeling results will be the number of products that must be made in each passenger class. Sensitivity analysis is carried out to find out how much the parameter change affects the optimal solution. At this stage, there will also be a comparison of optimization results with previous methods carried out by the company.

\section{RESULTS AND DISCUSSION}

At the beginning of the week of January 2020, from the existing condition the total production cost incurred by six airlines was IDR $237,967,825.95$ where the total cost is the actual value without optimizing inventory. The result of optimization obtained the total cost of production arising in the amount of IDR 184,186,987.50 and a significant decrease occurred in the type of production cost of $23 \%$ although there are additional costs on holding costs and variable production costs. This shows that by doing optimization, the company is able to make potential savings on total production costs of around IDR 53 million or about $23 \%$

Mix Integer Linear Programming Model on production process optimization issues in the case study of the airline catering industry that has been designed and outlined in the mathematical model and Lingo model. Completion using Lingo can run well and has produced an optimal solution.

\section{REFERENCES}

[1] I.N. Pujawan, "Schedule nervousness in a manufacturing : a case study," Production Planning and Control, vol. 15 no.5, pp. 515-524, 2004 doi: 10.1080/09537280410001726320

[2] O. Tang and R.W. Grubbstrom, "Modelling reschedulling activities in a multi period production-inventory system," International Journal of Production Economics, vol. 68, 2000, pp. 123-135

[3] D. Rahmani, R. Ramezania, P. Fattahi, and M. Heydari, "A robust optimization model for multi-product two stage capacitated production planning under uncertainly," Applied Mathematical Modelling, vol. 37, 2013, pp. 8957-8971 doi: 10.1016/j.apm.2013.04.016 